\title{
The Effect of Drought Phenomenon on the Surface of Groundwater Aquifer in Qazvin Plain in Iran
}

\author{
Vahid Isazade ${ }^{1}$, Abdul Baser Qasimi²*, Ara Toomanian ${ }^{3}$, Esmail Isazade $^{4}$ \\ ${ }^{1,3}$ Department of Geographic Information System, Geography Faculty, University of Tehran, Iran(vahidisazade75@gmail.com, \\ a.toomanian@ut.ac.ir) \\ ${ }^{2}$ Department of Geography, Education Faculty, Samangan University, Samangan, Afghanistan (qasimi.abdul.a@gmail.com, \\ qasimi.abdul.a@smgu.edu.af) \\ ${ }^{4}$ Department of Urban Panning, Kharazmi University, Tehran, Iran (ismailisazadeh75@gmail.com) \\ ${ }^{*}$ Correspondance: qasimi.abdul.a@gmail.com
}

\begin{abstract}
As one of the most catastrophic atmospheric events, drought affects various aspects of the environment. Groundwater resources are one the sectors that are influenced by long-term droughts and received insufficient attention compared to other aspects of the environment. Rainfall data collected by 23 metrological stations for 20 years $(2005,2010,2015,2020)$ was used to investigate the drought event and its situation in Qazvin plain, the central plateau of Iran. Drought characteristics are evaluated using the 24month standardized precipitation index (SPI). The results of SPI indicated that insufficient precipitation, excessive use of groundwater for irrigation, and utilization of uncontrolled wells caused a significant reduction in groundwater aquifers from 2015 to 2020 . To assess the performance of the SPI, a five-year moving average of available precipitation data was calculated, and the result confirmed the outcomes of SPI. Appropriate geostatistical interpolation methods are used to generate maps of drought zoning. Based on the results of this investigation in the northeastern part of the study area, June and November had the highest and the lowest rate of drought, respectively. The linear regression between the annual average of precipitation and the changes of groundwater aquifer level exposed a significant correlation of $R^{2}=0.4253$. Furthermore, linear regression between 24-month SPI and groundwater aquifer level indicated a correlation of $R^{2}=0.614$. Considering the results of this study, the reduction of groundwater aquifer levels in Qazvin plain from 2015 to 2015 exposed a significant negative difference compared to previous years (2005 to 2010).
\end{abstract}

Keywords: Drought, Groundwater aquifer, Geo-statistics, Precipitation Index, Qazvin plain

Received: Nov. 01 ${ }^{\text {st }}, 2021 /$ Accepted: Dec. $27^{\text {th }}, 2021 /$ Online: Dec. $30^{\text {th }}, 2021$

\section{Introduction}

Drought is a natural phenomenon and disaster and happens in any geographical region across the world. However, it's more common in semi-arid regions(Fadhil Al-Quraishi et al., 2021). Groundwater occurs in all climatic zones, such as those with high precipitation averages and those attributed to low rainfall averages (Gaznayee \& Al-Quraishi, 2019). The extensive water reserve beneath Earth's surface is a crucial source for humans and ecosystems (Taylor et al., 2013). By supplying 36\% of water for drinking and $42 \%$ of farming water, groundwater is a significant freshwater source globally (Kourakos et al., 2019). Throughout the existing condition of the 'Anthropocene', groundwater resources are under massive stress due to natural and 
anthropogenic stresses (Gleeson et al., 2020). Naturally, groundwater is sensitive to variability and change in hydroclimate conditions (Cuthbert et al., 2019). For instance, an increase in the intensity of evaporation as the consequence of a warmer climate decreases groundwater recharge, which is also responsive to landscape features, such as soil and vegetation characteristics (Hartmann et al., 2017; Oliveira et al., 2017).

Moreover, groundwater accessibility is also affected by human water withdrawals to maintain different socioeconomic activities (Lall et al., 2020). Uptakes from groundwater resources have risen significantly in recent years due to global population growth and water use per capita (de Graaf et al., 2019). Groundwater is a trustworthy resource of fresh water, which covers human water demands. Its gradual response to climatological circumstances makes it a massive buffer against climate variability, as well as drought (Calow et al., 2010). It is projected that $35 \%$ of the Earth's surface does suffer various forms of drought in several given years (Calow et al., 2010). This puts into disbelief whether groundwater will meet the growing water demand (Mosley et al., 2015), given the emerging depletion threats from a reduced recharge rate in the face of increasing demand (Wada et al., 2010).

During the recent drought events, groundwater has been heavily exploited for various agricultural, urban, and industrial uses. The impacts of the droughts are not limited to Iran, (Gaznayee \& Al-Quraishi, 2019) exhibited that the drought has severely affected crop yields in Erbil Province of Iraq within the last two decades. Although groundwater is considered one of the most crucial water resources in the world, it is not considered in many drought studies (Shakiba et al., 2010).

Accessibility to groundwater resources is vital in populated and dry parts of the world (Suter et al., 2019; Erler et al., 2019). Surface water is declining sharply as the temperature rises (Famiglietti et al., 2011 \& Wisser et al., 2009 \& Qin et al., 2019), and it increases the competition for surface water resources. (Joodaki et al., 2014 \& Voss et al., 2013 \& Kahil et al., 2015). Groundwater drought occurs in periods while the volume of rainfall in that period is less than the long-term average (Peters et al., 2003). When the groundwater aquifer system is influenced by drought, initially the dewatering, then the surface, and finally the groundwater aquifer discharge decreases (Van Lanen et al., 2000). The rise of global and local temperature can influence physical and chemical changes of the earth's surface process and eventually affects groundwater quality. (Brons et al., 1991; Griffioen and Appelo, 1993; Bonte et al., 2013a, 2013b, 2013c; Jesubek et al., 2013). Various research has been done on the impact of drought on the aquifer surface. Weider and Boutt (2010) revealed that groundwater responses to rainfall anomalies are more dissimilar than the responses exposed by streamflow. Consequently, Bloomfield et al. (2019), Kumar et al. (2016), and Stoelzle et al. (2020) discovered that the drought of groundwater happens in specific geographic regions and can be affected by the hydrological attributes and storage capability of these regions. Al-Quraishi et al. (2021) conducted a time series analysis of the drought based on NDVI, SPI, and NDWI. The result exposed a significant correlation between SPI and precipitation.

The drought affects the groundwater and vegetation(H. Gaznayee \& Al-Quraishi, 2020) demonstrated a massive reduction of the vegetation-covered area affected by drought severity in the Iraqi Kurdistan Region. Javadanian et al. (2016) evaluated the correlation between the amount of groundwater usage and the reduction of groundwater aquifer level in Damaneh of Isfahan and showed that the decrease in groundwater level has a direct effect on the creation and expansion of subsidence. Within the last two decades, Qazvin plain experienced catastrophic events like drought severity drying of seasonal rivers, which caused a massive reduction of surface water and an eventually significant reduction in the level of groundwater aquifer (Rezai et al., 2010). In the last two decades, Qazvin plain-faced massive changes.

Drought occurrence, surface water reduction, drying of seasonal rivers, and significant decreases in groundwater aquifer levels are the most catastrophic events of the last 20 years in this area. Therefore, this study investigates the impacts of the drought events on the decline of groundwater resources in Qazvin plain over the last two decades. The decrease in groundwater aquifers level in Qazvin plain was increased significantly, which can cause economic, social, and environmental crises in this region. Drought, climate change, land-use change, and uncontrolled drilling of the wells are the influencing factors of the groundwater crisis in Qazvin plain. 
According to current evidence, the annual consumption of groundwater in Qazvin plain is 200 million cubic meters, while only 1.4 million cubic meters of this consumption is being recharged by precipitation water. Less than $10 \%$ of the harvested water is used for drinking and industrial sectors, while about $90 \%$ of this water is consumed in the agricultural sector. Qazvin plain, with an area of $4220 \mathrm{~km} 2$ and an average alluvial thickness of 300 meters, has a potential of 1.2 billion cubic meters of groundwater (Fallah et al., 2016). This study investigates the relationship between fluctuations in groundwater aquifer level and the drought impacts using the standardized precipitation index (SPI) in Qazvin plain, Iran.

\section{Study Area}

Qazvin Province is situated in the central region of Iran and covers 15,623 km2, which lies between latitudes of $35^{\circ} 24^{\prime}-36^{\circ} 48^{\prime} \mathrm{N}$ and longitudes of $48^{\circ} 44^{\prime}-50^{\circ} 51^{\prime} \mathrm{E}$. Sharing borders with Mazandaran to the north, Zanjan and Hamedan to the west, Tehran to the east, and Markazi Province to the south. Qazvin plain has an annual average temperature of $13^{\circ} \mathrm{C}$, and annual precipitation of about $0.32 \mathrm{~m}$ in Qazvin Province. Qazvin plain has a dry climate with hot summer and cold winter (Figure 1). The groundwater depth in this area varies between 28 to $35 \mathrm{~m}$ from ground level. Qazvin plain has $3500 \mathrm{~km} 2$ fertile agricultural lands divided into two parts based on the source of irrigation water. The irrigation system of the northern part of Qazvin plain has been supplied through the Taleghan river in the last thirty years, and nowadays, this river is not capable of supplying the demanded water for this area. Therefore cultivators are shifting toward groundwater as an available alternative.

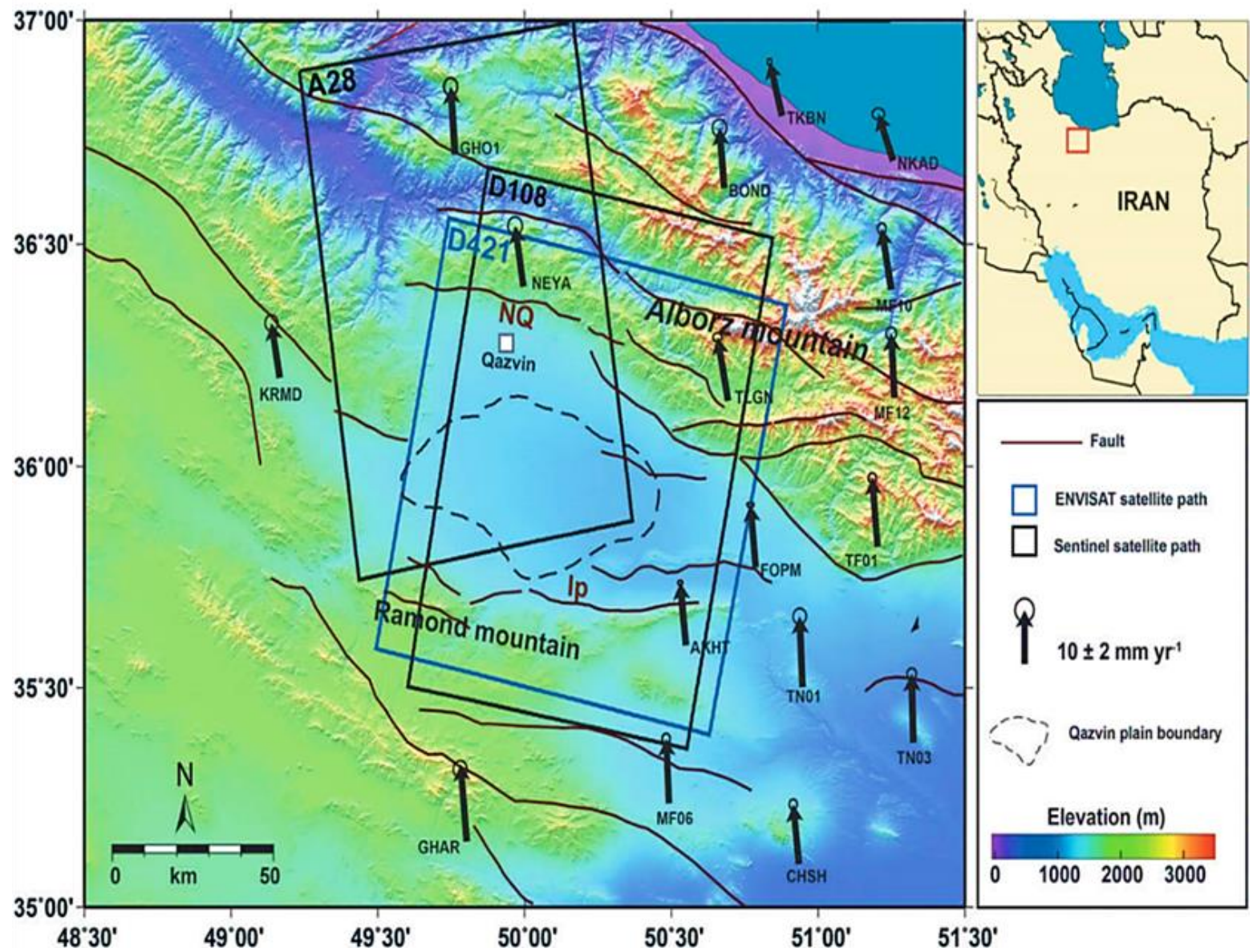

Figure 1. Inset Outline map of Iran on the right side and the red frame indicates specified research area, the main figure on the left presents the tectonic map of the study area Djamour et al. (2010) 


\section{Materials and Methods}

This study used the standard precipitation index (SPI) and precipitation data, obtained from meteorological stations to evaluate drought events in the Qazvin plain. The SPI values were calculated employing (DIP) software. The 24-month SPI index allows the evaluation of groundwater resources; therefore, the 24-month SPI index was used in this study. The interpolation methods are used to predict values for each pixel based on available data points within the specified study area. Three methods of interpolation, inverse distance weighted (IDW), radial basis functions (RBF), and kriging, were examined and the best interpolation technique was selected by analyzing Root Mean Square Error (RMSE) values, equation (1). Research workflow is presented in Figure (2).

$$
R M S E=\sqrt{\frac{\sum_{i=1}^{n}(Z(X i)-Z *(X i))}{n}}
$$

Where, $\mathrm{Z} *$ is the predicted value and $\mathrm{Z}$ is the observed value of the variable in position $\mathrm{x}_{\mathrm{i}}$, and $\mathrm{n}$ is the number of observations.

Correlation and linear regression were calculated to evaluate the relationship between drought events and groundwater fluctuations using suitable software like SPSS and excel.

\subsection{Standardized Precipitation Index (SPI)}

The Standardized Precipitation Index (SPI) is a widely used index to characterize drought events on a range of timescales. The SPI calculation involves fitting a probabilistic gamma density function to a specific time series rainfall data. The SPI can be created for differing periods of 1-to-36 months, using monthly input data. This was evaluated independently for each month and location for an overall review of drought concepts and modeling. Lack of sufficient rainfall is considered the leading cause of the drought.

Furthermore, the spatial distribution, amount, and precipitation time are essential to define its effectiveness. At the same time, the storage of the water depends on the available water reservoir, water demands, and its usage as well. Thus, drought is a persistent term for water scarcity and occurs naturally when an area receives less than regular rainfall for several months. Where the rainfall is less than the long-term average, the output value of SPI is negative (Gocic and Trajkovic, 2014). Unlike other land indices, the SPI is not heavy to use. The SPI gets only time-series rainfall data as input (Smack tin \& Hughes, 2004). The SPI operates based on Normalized data, and this index is spatially constant and can be evaluated in different regions (Guttman, 1998). The SPI index is calculated using Equation (2).

$$
S P I=\frac{x i \bar{x}}{\sigma}
$$

Where $\mathrm{x}$ is the rainfall data for the selected period of years (i), $\overline{\mathrm{x}}$ is long-term mean of precipitation (xi), and $\sigma$ is the standard deviation of data for the specified timescale.

\subsection{Inverse Distance Weighted (IDW)}

The inverse distance weighted (IDW) technique estimates the value of each point based on its distance to the observed points. The weights assigned to the predicted points are regulated by weighting parameters of IDW, such as distance and power. Greater powers decrease the effect of points farther from the predicted point, and smaller powers distribute weights more consistently between neighboring points. Obviously, this technique only respects distances, regardless of the position and arrangement of points. That, points with an equal distance related to the observed point will receive the same weight (Gong et al., 2014). The inverse distance weighting technique is calculated based on Eq. (3): 


$$
\lambda_{i}=\frac{\sum_{i=1}^{n}\left(\frac{Z_{i}}{d_{i}}\right)}{\sum_{i=1}^{n}\left(\frac{1}{{d_{i}}^{p}}\right)}
$$

$\lambda_{i}$ is the point to be predicted, $\mathrm{n}$ is the number of points, $\mathrm{z}_{\mathrm{i}}$ is the value of the observed point for location (i), $\mathrm{d}$ is the distance and $\mathrm{p}$ is the power.

\subsection{Krigning}

Kriging is one of the most widely used geostatistical interpolation methods that consider both the distance and the degree of variation between observed data points while predicting values to the unknown points (Rocha et al., 2018). It is a multistep procedure; it comprises exploratory statistical evaluation of the data. Kriging is essentially a statistical approach to compute weights regarding adjacent values. It is also recognized as BLUE (Best Linear Unbiased Estimator).

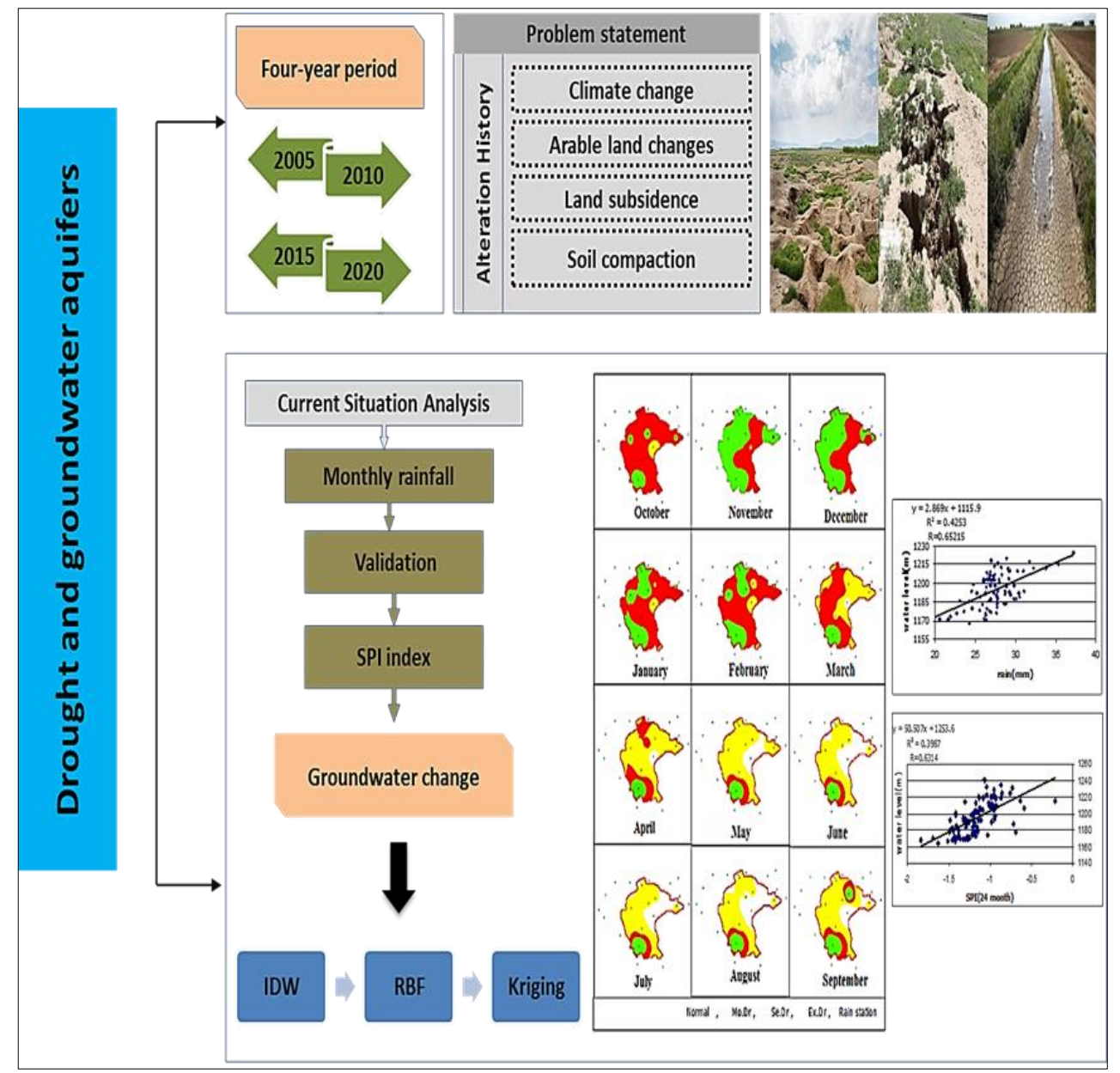

Figure 2. Research workflow

\section{Results and Discussion}

The SPI is computed for the 24-month timescale and is presented in Figure 3. The results of drought analysis for the 24-month timescale in Qazvin plain are presented in Figure 3. The result of drought severity from 2010 to 2015 is more significant due to its intensity. To determine the dry year, ranks were given to each year based on drought intensities. According to the results of the SPI index, Qazvin plain had the lowest moisture from 2015 to 2020 and was determined as the driest years. To validate the output of SPI, a five-year moving average of precipitation was calculated, and the result of SPI was confirmed. Among the interpolation methods IDW, 
RBF, and kriging, based on their Root Mean Square Error (RMSE), The IDW interpolation technique with the least error was recognized as the best method for data interpolation this research. The spatial expansion of drought range in Qazvin plain presented in Figure 3, and the results of SPI revealed in 2010-2015, November and December had the highest humidity with a percentage of 64.14 and 60.93, respectively. June received the lowest with a percent of (7.07). August with (33.34\%) of the area experienced the highest rate of severe drought. The east and northeastern parts of the study area had unfavorable humidity and moisture conditions in the second half of the investigated years, while the southwestern parts are in a normal condition. The maps of drought periods are presented in (Figure 4).

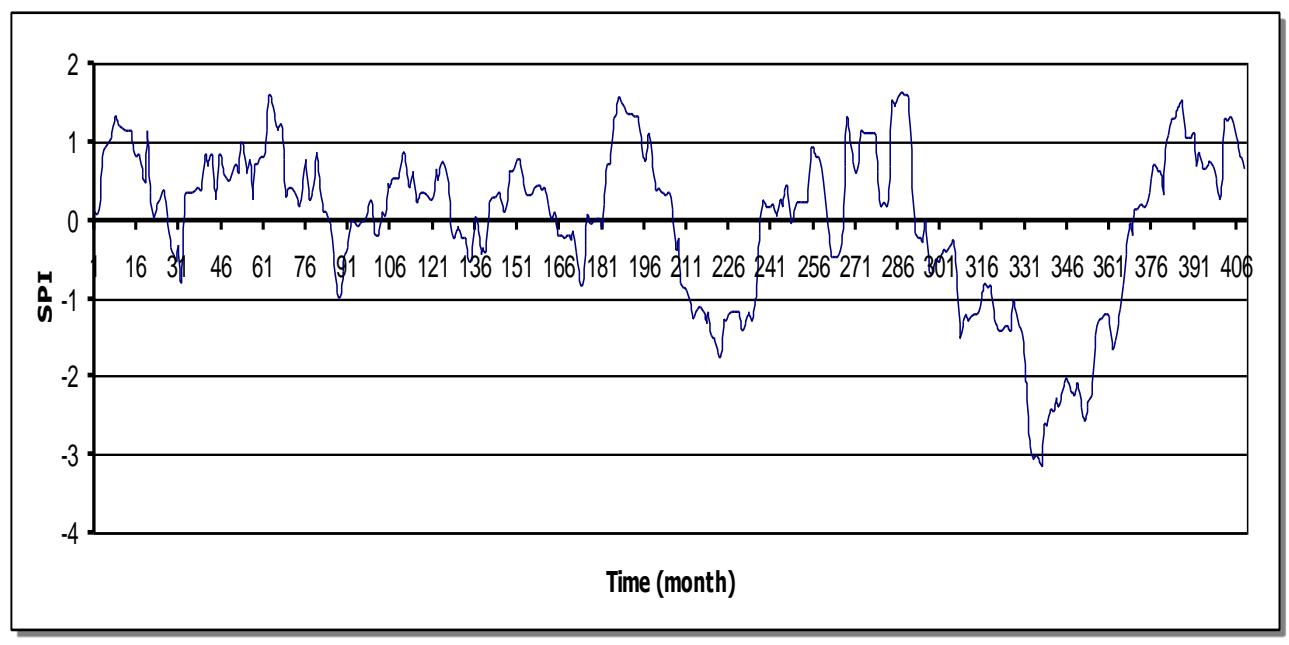

Figure 3. Twenty-four-month time series of SPI index of Nusrat Abad station from 2010 -2015 to 2015 to 2020.

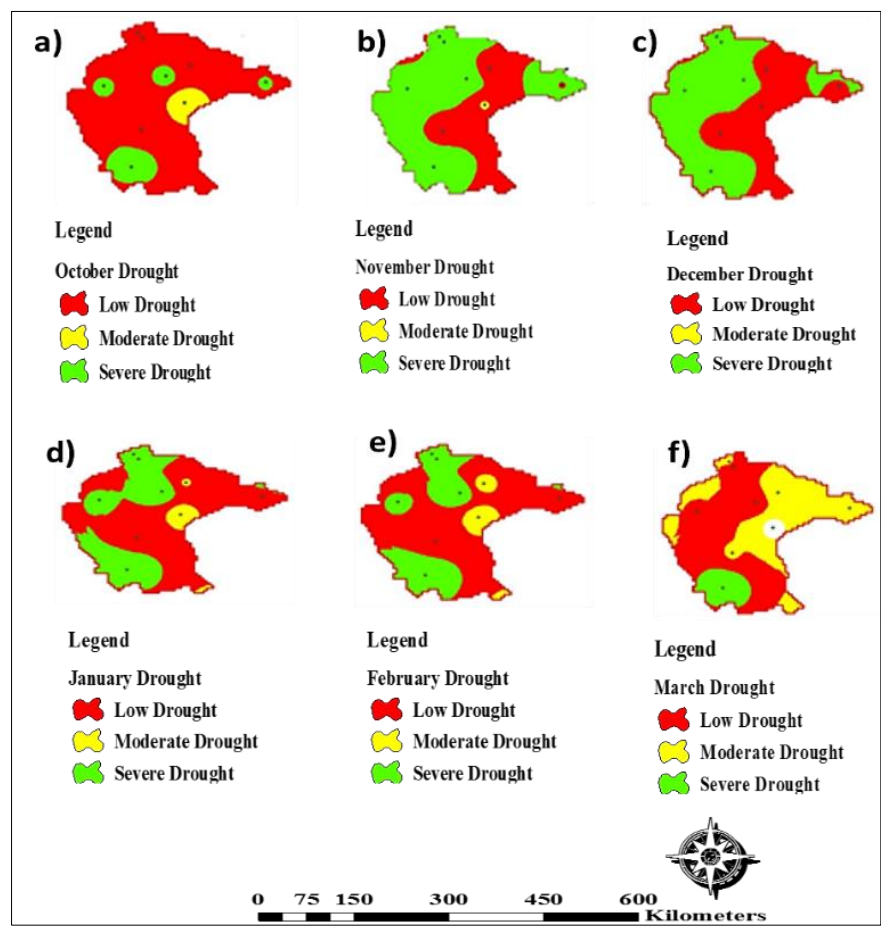

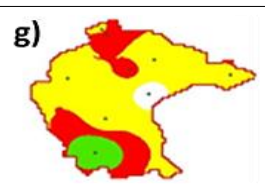

Legend

April Drought

L ow Drought

3 Moder ate Drought

3 Severe Drought

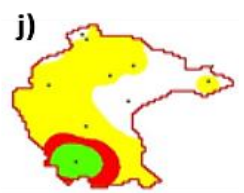

Legend

July Drought

3 Low Drought

7 Moderate Drought

$\sim 3$ Severe Drought

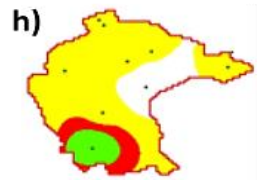

Legend

May Drought

CS Low Drought

$\checkmark 3$ Moderate Drought

13 Severe Drought

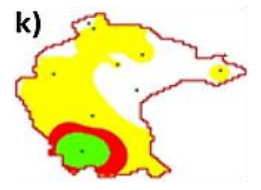

Legend

August Drought

Low Drough

$\sqrt{3}$ Mod erate Drough

S Severe Drought

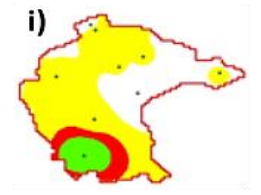

Legend

June Drought

Low Drought

7 Moderate Drought

3 Severe Drought

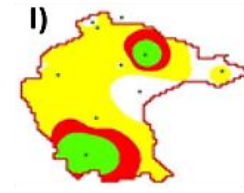

Legend

September Drought

Low Drought

$\sqrt{3}$ Moderate Drought

$\approx$ Severe Drought

Figure 4. Drought partitioning in Qazvin plain using IDW technique (a, b, c, d, e, f), Drought zoning in Qazvin plain, obtain ed by $\operatorname{IDW}(\mathrm{g}, \mathrm{h}, \mathrm{i}, \mathrm{j}, \mathrm{k}, \mathrm{l})$ 


\subsection{Influences of drought on groundwater resources}

In order to inveterate the effects of drought on groundwater, the monthly hydrograph of the study area is used to evaluate the correlation between groundwater aquifer level, and rate of precipitation. The result exposed the negative impacts of the drought on groundwater aquifers. The hydrograph of the study area shows a negative trend. According to this trend, the level of groundwater aquifer decreased 1-meter per-year in the last 13 years. The statistical information obtained from correlation coefficients between monthly rainfall and monthly water level fluctuations is presented in Table 1. The low correlation coefficient between precipitation and water level occurs mainly due to two reasons. The infiltration of precipitation water and the delay of snowmelt that causes a delay in reaching to the groundwater aquifer.

Furthermore, the monthly rainfall and the groundwater abstraction level are not regular. Table 1 shows the correlation coefficients of groundwater aquifer level and rainfall for one-to-four months ago. These coefficients show that the precipitation of three months ago has the highest correlation with the surface of the groundwater aquifer. This correlation coefficient is significant in confidence (1\%), shown in Figure 5.

Table 1. Correlation coefficients between monthly precipitation and groundwater aquifer level.

Coefficients Simultaneous a month ago, two months ago, Three months ago,

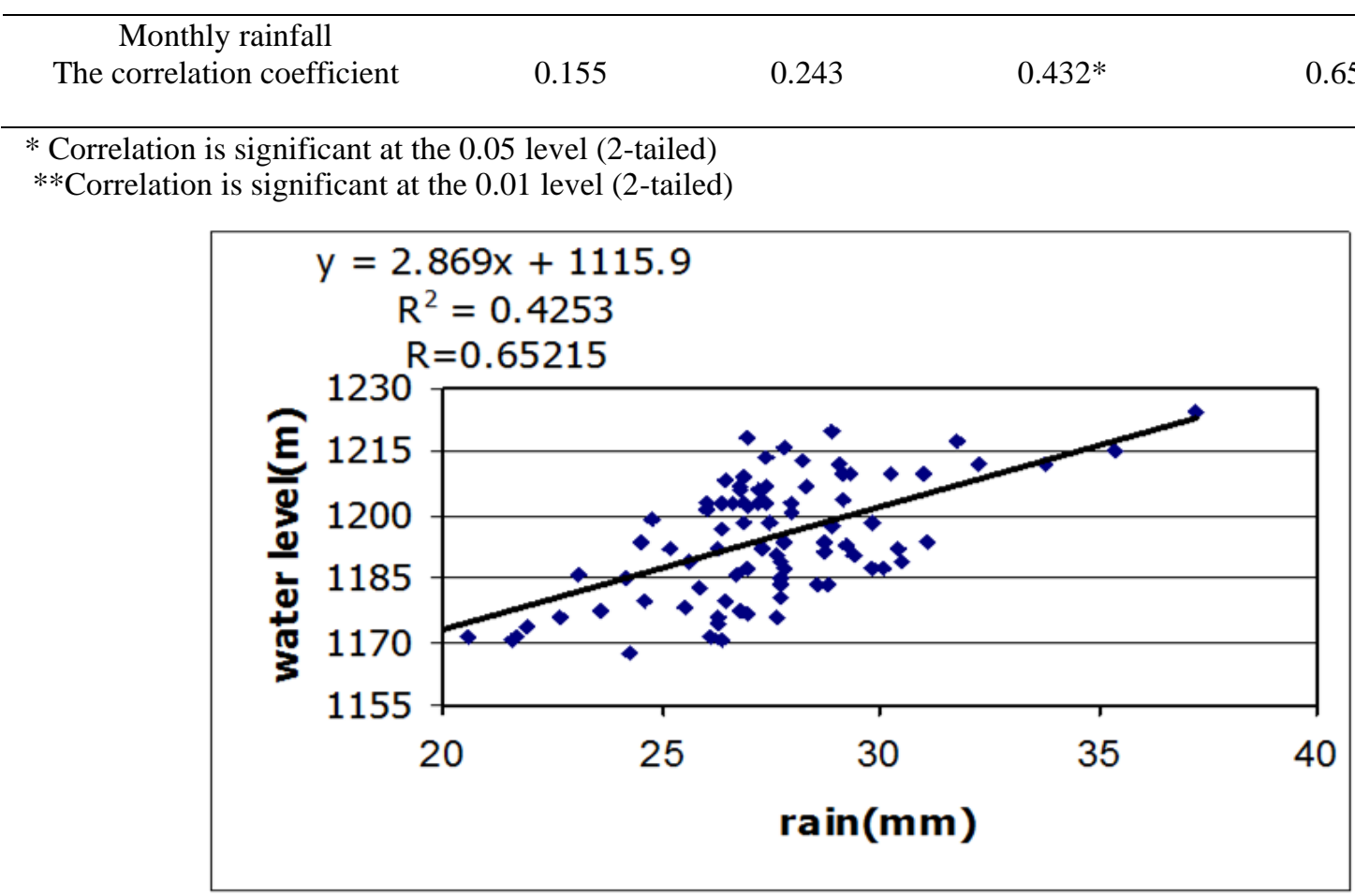

Figure 5. Linear regression between monthly precipitation and water level Changes in Qazvin plain

Correlations between 24-month SPI and groundwater level are evaluated and showed that the groundwater aquifer level of Qazvin plain in 2010-2015 had a good correlation with 24-month SPI, therefore the correlation coefficient with a value of 0.634 and a significance of 0.01 was obtained. Figure 6 . The findings of this study proved that drought is the main reason for the water table decline in the Qazvin plain. However, other factors such as the overdraft of groundwater, population growth, and mismanagement are involved with the decline of groundwater in this plain. 


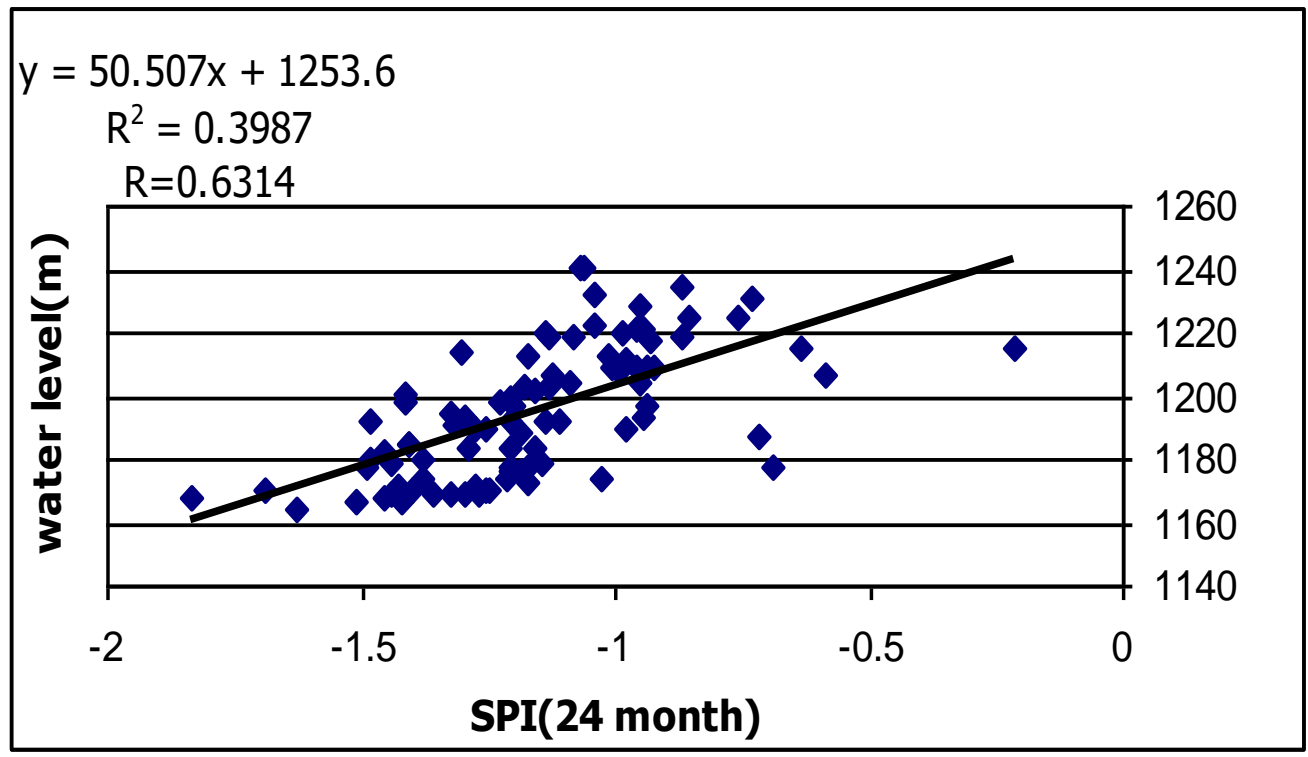

Figure 6. Linear regression between 24-month SPI and groundwater Aquifer surface

\section{Conclusion}

Drought is a natural disaster that affects human life, sustainable development, and the earth's ecosystem. Evaluated 24-month timescale SPI results demonstrate a five-year severe drought in Qazvin plain occurred from 2010 to 2015. Three interpolation methods, IDW, kriging, and RBF were evaluated, and the IDW method with the least root mean error (RMSE) exposed more feasibility as the best interpolation method for this research. Considering the outputs of the drought severity zoning, all the regions of the Qazvin plain exposed unfavorable conditions within the specified years of the study, except the southeastern regions, which have a normal condition in all months of the years. Based on the monthly average of precipitation, drought conditions vary between the regions. However, considering the overall condition across the study area, the most severe droughts during the last two decades occurred in August and June, and the severity was increased in August, where $33.34 \%$ of the research area was covered by severe drought. According to the study area hydrograph, the groundwater aquifer level has shown a negative trend in the last 20 years. Based on this trend, the water level decreased 1-meter per year and reached 2-meters per year from 2010 to 2020. Findings of this study indicate that groundwater aquifer level has a good and significant correlation with standardized precipitation index with a 24-month timescale. This study exposed a substantial decrease in groundwater aquifer levels from 2010 to 2020 compared to 2005 to 2010 due to drought. However, the drought is not the only influencing factor for reducing the groundwater aquifer in Qazvin plain. Population growth, uncontrolled drilling of the wells, and agricultural activities are also responsible for this issue. It requires a proper planning and management system to protect and limit the water usage during the drought crisis contrarily this region will not be capable of supporting life in the future.

\section{Acknowledgment}

The authors would like to thank the constructive comments from the anonymous reviewers.

\section{References}

Bloomfield, J. P., Marchant, B. P., \& McKenzie, A. A., 2019. Changes in groundwater drought associated with anthropogenic warming, Hydrol. Earth Syst. Sci., 23, 1393-1408, https://doi.org/10.5194/hess-23. 
Cuthbert, M., O. et al., 2019. Observed controls on resilience of groundwater to climate variability in sub-Saharan Africa. Nature $572,230-234$.

Calow, R., C., MacDonald, A. M., Nicol, A. L., \& Robins, N. S., 2010. Ground Water Security and Drought in Africa: Linking Availability, Access, and Demand. Ground Water, 48(2), 246-256.

Choi, M., J.M., Jacobs, M.C., Anderson \& Bosch D. D., 2013. Evaluation of drought indices via remotely sensed data with hydrological variables. Journal of Hydrology, 476: 265-273.

De graaf, I. E. M., Gleeson, T., van Beek, L. P. H., Sutanudjaja, E. H., \& Bierkens, M. F. P., 2019. Environmental fow limits to global groundwater pumping. Nature 574, 90-94 (2019).

Djamour, Y., P. Vernant, R. Bayer, H. R. Nankali, J. F. Ritz, J. Hinderer, Y. Hatam, et al., 2010. GPS and Gravity Constraints on Continental Deformation in the Alborz Mountain Range, Iran. Geophysical Journal International 183 (3): $1287-1301$. doi:10.1111/j.1365-246X.2010.04811.x.

Erler, A. R. et al., 2019. Evaluating climate change impacts on soil moisture and groundwater resources within a lake-affected region. Water Resour. Res. 55, 8142-8163 Famiglietti, J. S. et al. Satellites measure recent rates of groundwater depletion in California's Central Valley. Geophys. Res. Lett. 38 (L03403), 1-4 (2011).

Falah, F., Ghorbani-Nejad, S., Rahmati, O., Daneshfar, M., \& Zeinivand, H., 2016. Applicability of generalised additive model in groundwater potential modelling and comparision its performance by bivariate statistical methods, Geocarto International, 32(10), pp. 1069-1089.

Fijani, E., Nadiri, A. A., Moghaddam, A. A., Tsai, F. T. C. \& Dixon, B., 2013. Optimization of DRASTIC method by supervised committee machine artificial intelligence to assess groundwater vulnerability for Maragheh-Bonab plain aquifer, Iran. Journal of Hydrology 503, 89-100.

Fadhil Al-Quraishi, A. M., Gaznayee, H. A. A., \& Messina, J. P. (2021). Drought severity trend analysis based on the Landsat timeseries dataset of 1998-2017 in the Iraqi Kurdistan Region. IOP Conference Series: Earth and Environmental Science, 779(1). https://doi.org/10.1088/1755-1315/779/1/012083

Gaznayee, H. A. A., \& Al-Quraishi, A. M. F. (2019). Analysis of agricultural drought's severity and impacts in Erbil Province, the Iraqi Kurdistan region based on time series NDVI and TCI indices for 1998 through 2017. Journal of Advanced Research in Dynamical and Control Systems, 11(11), 287-297. https://doi.org/10.5373/JARDCS/V11I11/20193198

Gaznayee, H., \& Al-Quraishi, A. (2020). Identifying Drought Status in Duhok Governorate (Iraqi Kurdistan Region) from 1998 through 2012 using Landsat Time Series Dataset. Journal of Applied Science and Technology Trends, 1(1), 17-23. https://doi.org/10.38094/jastt1112

Gleeson, T. et al., 2020. Illuminating water cycle modifcations and Earth system resilience in the Anthropocene. Water Resour. Res. 56, 1-24.

Gourbesville, P., 2008. Challenges for integrated water resources management. Physics and Chemistry of the Earth, 33(5): 284-289.

Gocic, M., Trajkovic, S., 2014. Spatiotemporal characteristics of drought in Serbia. J. Hydrol. 510, $110-123$.

Guttman, N.B., 1998. Comparing the Palmer Drought Index and the Standardized Precipitation 409 Index. American Water Resources Association, 34 (1), 113-121

Gong, G., Mattevada, S., \& Bryant, S., 2014. Comparison of the accuracy of kriging and IDW interpolations in estimating groundwater arsenic concentrations in Texas. Environ Res; 130(0):59-69.

Hartmann, A., Gleeson, T., Wada, Y., \& Wagener, T., 2017. Enhanced groundwater recharge rates and altered recharge sensitivity to climate variability through subsurface heterogeneity. Proc. Natl. Acad. Sci. 114, 2842-2847 (2017).

Hellwig, J., 2018 Grundwasserdürren in Deutschland von 1970 bis, Korrespondenz Wasserwirtschaft, 12, 567-572, https://doi.org/10.3243/kwe2019.10.00.

Stahl, K., 2021. Model outputs: Groundwater and baseflow stress tests in Germany, FreiDok, https://doi.org/10.6094/UNIFR/167379.

Javadanian, H., \& Ahmadi Darani, M., 2016. Irregular abstraction of groundwater resources and regional meeting: a case study of the city of Isfahan, Journal of Water and Wastewater Science and Engineering, 1(1), pp. 49-60.

Joodaki, G., Wahr, J., \& Swenson, S., 2014. Estimating the human contribution to groundwater depletion in the Middle East, from GRACE data, land surface models, and well observations. Water Resour. Res. 50, 2679-2692.

Kumar, R., Musuuza, J. L., Van Loon, A. F., Teuling, A. J., Barthel, R., Ten Broek, J., Mai, J., Samaniego, L., \& Attinger, S., 2016. Multiscale evaluation of the Standardized Precipitation Index as a groundwater drought indicator, Hydrol. Earth Syst. Sci., 20, 1117-1131, https://doi.org/10.5194/hess-20-1117-2016.

Kahil, M. T., Dinar, A. \& Albiac, J., 2015. Modeling water scarcity and droughts for policy adaptation to climate change in arid and semiarid regions. J. Hydrol. 522, 95-109.

Kourakos, G., Dahlke, H. E., \& Harter, T., 2019. Increasing groundwater availability and seasonal base fow through agricultural managed aquifer recharge in an irrigated basin. Water Resour. Res. 55, 7464-7492.

Lall, U., Josset, L., \& Russo, T., 2020. A snapshot of the world's groundwater challenges. Annu. Rev. Environ. Resour. https://doi.org/10. 1146/annurev-environ-102017-025800. 
Mosley, L.M., 2015. Drought impacts on the water quality of freshwater systems; review and integration. Earth-Science Reviews, $140,203-214$.

Oliveira, P. T., \& S. et al., 2017. Groundwater recharge decrease with increased vegetation density in the Brazilian cerrado. Ecohydrology 10, e1759.

Peters, E., P.J.J.F. Torfs, H.A.J. Van Lanen and G. Bier. 2003. Propagation of drought through groundwater, a new approach using linear reservoir theory. Journal name, 17: 3023-3040.

Qin, Y. et al., 2019. Flexibility and intensity of global water use. Nat. Sustain. 2, 515-523.

Rezai, R., Maleki, A., Sarifi, M., \& Ghavami, A., 2010. Evaluation of chemical pollution of groundwater resources in downstream areas of Sanandaj city landfill, Journal of Kurdistan University of Medical Sciences, Vo. 15, pp. 1989-1998.

Rajasooriyar, L. D., Boelee, E., Prado, M. C., \& Hiscock, K. M., 2013. Mapping the potential human health implications of groundwater pollution in southern Sri Lanka. Water Resources and Rural Development 1-2, $27-42$.

Rocha, A., Adeli, H., Paulo, L., and Costanzo, S., 2018. Trends and Advances in Information Systems and Technologies. Springer, New York, NY, Vol. 1.

Suter, J. F., Rouhi Rad, M., Manning, D. T., Goemans, C., \& Sanderson, M. R., 2019. Depletion, climate, and the incremental value of groundwater. Resour. Energy Econ. https:// doi. org/ 10. 1016/j. resen deco. 2019. 101143.

Shakiba, A., Mirbagheri, B., \& Kheiri, A., 2010. Drought and its impact on groundwater resources in the east Kermanshah province. Geography (Journal of Geographical Society of Iran), 8(25): 105-124 (in Persian).

Stoelzle, M., Staudinger, M., Stahl, K., \& Weiler, M., 2020. Stress testing as complement to climate scenarios: recharge scenarios to quantify streamflow drought sensitivity, P. IAHS, 383, 43-50.

Smakhtin, V.U., \& Hughes, D.A., 2004. Review, Automated estimation and analyses of drought 475 indices in South Asia. Working Paper 83, Drought Series paper 1, Colombo, Sri Lanka. 476 International Water Management Institute, 24pp.

Taylor, R., G. et al., 2013. Ground water and climate change. Nat. Clim. Change 3, 322-329.

Voss, K., A. et al., 2013. Groundwater depletion in the Middle East from GRACE with implications for Tran's boundary water management in the Tigris-Euphrates-Western Iran region: groundwater depletion in the Middle East from GRACE. Water Resour. Res. 49, 904-914.

Van Lanen, H.A.J., \& Peters, E., 2000. Definition, effects and assessment of groundwater droughts. In J. S. Vogt, Drought and Drought Mitigation in Europe (pp. 49-61). Dordrecht: Kluwer.

Weider, K., \& Boutt, D. F., 2010. Heterogeneous water table response to climate revealed by 60 years of ground water data, Geophys. Res. Lett., 37, L24405, https://doi.org/10.1029/2010GL045561.

Wisser, D., Fekete, B. M., 2009. Vorosmarty, C. J. \& Schumann, A. H. Reconstructing 20th century global hydrography: a contribution to the Global Terrestrial Network- Hydrology (GTN-H). Hydrol. Earth Syst. Sci. Discuss. 6, $2679-2732$.

Wada, Y. et al., 2010. Global depletion of groundwater resources. Geophys. Res. Lett. 37, L20402. 